\title{
Statistical Regions of the United Kingdom ${ }^{1}$
}

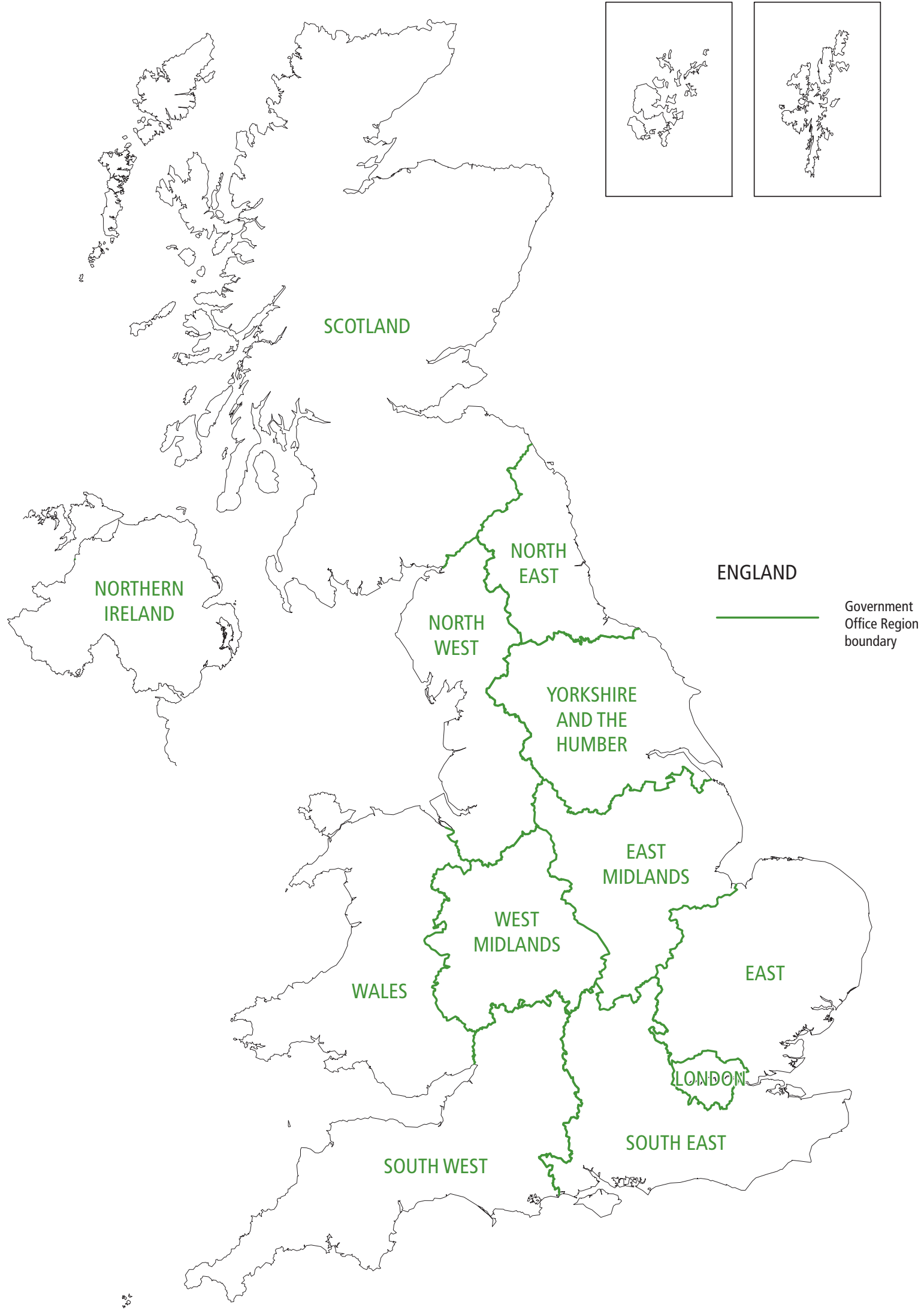

1 For the purposes of statistical analyses, the United Kingdom has been divided into 12 'statistical regions'. 